Volume 5 Issue 2

Californian Journal of Health Promotion 2007

Table of Contents

Content

$\underline{\text { Pages }}$

CJHP Editorial Board

Table of Contents

The Editor's Corner

i-ii

iii-iv

$\mathbf{v}$

\section{RESEARCH AND THEORY}

Factors Affecting the Consumption of Away-from-Home Foods in Hawai i Residents

Angelina M. Ahedo, Taryn W. Lee, Joan Pan, Katie M. Heinrich, Stefan Keller, Jay

Maddock

Yoga, Physical Education, and Self-Esteem: Off the Court and Onto the Mat for Mental Health

Kaci A. Bridges and Melody S. Madlem

Integrating Health Education into Clinical Settings

18-24

Theresa L. Byrd, Mary M. Hoke, Nell H. Gottlieb

Low Caloric Intake Among Mexican - American High School Students May Suggest

Food Insecurity and/or Insufficiency in the Household

Liset Leal-Vasquez, Tammy Wyatt, Ashley Love

Predictors of Smoking and Alcohol Use in Japanese and Japanese-American College Students

Michiyo Tomioka and Jay Maddock

To Hell and Back: Wounded Warriors Return Home to Fight Yet Another Battle

58-66

Kathy A. DeBarr

Effectiveness of an Intervention Regarding Weight Status of Selected New Mexico

Kindergarten Children and their Parent's Perceptions

Amanda Jones and Susan C. Forster-Cox

112-127
Cancer Screening Belief Scale - Chinese Version (CSBS-C): Validation on Scale Psychometric Properties Among a Chinese Worksite Population

$\mathrm{Su}-\mathrm{I} \mathrm{Hou}$

Gender Differences in Stress and Coping Among Adults Living in Hawai

Lauren A. Gentry, Jane J. Chung, Nandar Aung, Stefan Keller, Katie M. Heinrich, \& Jay E. Maddock

Applying the National Health Educator Competencies Update Project Model to

103-111 Health Education

Gary D. Gilmore, Larry K. Olsen, and Alyson Taub

Asian American Subgroup Differences in Sources of Health Information and

79-88

Predictors of Screening Behavior 


\section{Content}

Steven E. Shive, Grace X. Ma, Yin Tan, Jamil I. Toubbeh, Lalitha Parameswaran, Joseph Halowich

Health Promotion Research Methods: Preparing Students to Publish

Mirror, Mirror, Help Me Like My Body: Examining a Body Image Media Campaign

Sara B. Oswalt and Tammy J. Wyatt

Tracking Sleep Times to Reduce Tiredness and Improve Sleep in College Students

148-156

Daniel J. Prestwich, Linda L. Rankin, and Jeff Housman

Parents Attending a Family Weight Management Program Perceive Similar Home Fruit and Vegetable Accessibility, but Greater Child Proxy Agencyand Physical Activity Opportunity

Richard R. Rosenkranz, Karly. S. Geller, and David. A. Dzewaltowski 